\title{
The hybrid algorithm for the system of mixed equilibrium problems, the general system of finite variational inequalities and common fixed points for nonexpansive semigroups and strictly pseudo-contractive mappings
}

Poom Kumam ${ }^{1}$ and Phayap Katchang ${ }^{1,2^{*}}$

* Correspondence: $p$.

katchang@hotmail.com

${ }^{1}$ Department of Mathematics,

Faculty of Science, King Mongkut's

University of Technology Thonburi

(KMUTT), Bangmod, Bangkok

10140, Thailand

Full list of author information is

available at the end of the article

\begin{abstract}
In this article, we introduce a new iterative algorithm by the shrinking projection method for finding a common element of the set of solutions of generalized mixed equilibrium problems, the set of common solutions of general system of finite variational inequalities, the set of solutions of fixed points for nonexpansive semigroups and the set of common fixed points for an infinite family of strictly pseudo-contractive mappings in a real Hilbert space. We prove that the sequence converges strongly to a common element of the above four sets under some mind conditions. Our results improve and extend the corresponding recent results in literature work.
\end{abstract}

\section{Introduction}

Throughout this article, we assume that $C$ is a closed convex subset of a real Hilbert space $H$ with inner product and norm are denoted by $\langle. .$.$\rangle and \|$.$\| , respectively.$

Let $A, B: C \rightarrow H$ be two mappings. We consider the following problem of finding $\left(x^{*}, y^{*}\right) \in C \times C$ such that

$$
\left\{\begin{array}{l}
\left\langle\lambda A y^{*}+x^{*}-y^{*}, x-x^{*}\right\rangle \geq 0, \quad \forall x \in C, \\
\left\langle\mu B x^{*}+y^{*}-x^{*}, x-y^{*}\right\rangle \geq 0, \quad \forall x \in C,
\end{array}\right.
$$

which is called a general system of variational inequalities, where $\lambda \geq 0$ and $\mu \geq 0$ are two constants. The set of solution of (1) is denoted by $\operatorname{SVI}(C, A, B)$. In particular, if $A$ $=B$, then problem (1) reduces to finding $\left(x^{*}, y^{*}\right) \in C \times C$ such that

$$
\left\{\begin{array}{l}
\left\langle\lambda A y^{*}+x^{*}-y^{*}, x-x^{*}\right\rangle \geq 0, \quad \forall x \in C, \\
\left\langle\mu A x^{*}+y^{*}-x^{*}, x-y^{*}\right\rangle \geq 0, \quad \forall x \in C,
\end{array}\right.
$$

which is defined by Verma [1] (see also Verma [2]), and is called the new general system of variational inequalities. Further, if we set $B=0$, then problem (1) reduces to the classical variational inequality $\operatorname{VI}(C, A)$ which was originally introduced and studied by Stampacchia [3] in 1964.

(C) 2012 Kumam and Katchang; licensee Springer. This is an Open Access article distributed under the terms of the Creative Commons Attribution License (http://creativecommons.org/licenses/by/2.0), which permits unrestricted use, distribution, and reproduction in any medium, provided the original work is properly cited. 
By the system of variational inequality problems above, we extend into the general system of finite variational inequalities is to find $\left(x_{1}^{*}, x_{2}^{*}, \ldots, x_{M}^{*}\right) \in C \times C \times \cdots \times C$ and is defined by

$$
\left\{\begin{array}{l}
\left\langle\lambda_{M} A_{M} x_{M}^{*}+x_{1}^{*}-x_{M}^{*}, x-x_{1}^{*}\right\rangle \geq 0, \quad \forall x \in C, \\
\left\langle\lambda_{M-1} A_{M-1} x_{M-1}^{*}+x_{M}^{*}-x_{M-1}^{*}, x-x_{M}^{*}\right\rangle \geq 0, \quad \forall x \in C, \\
\vdots \\
\left\langle\lambda_{2} A_{2} x_{2}^{*}+x_{3}^{*}-x_{2}^{*}, x-x_{3}^{*}\right\rangle \geq 0, \quad \forall x \in C, \\
\left\langle\lambda_{1} A_{1} x_{1}^{*}+x_{2}^{*}-x_{1}^{*}, x-x_{2}^{*}\right\rangle \geq 0, \quad \forall x \in C,
\end{array}\right.
$$

where $\left\{A_{l}\right\}_{l=1}^{M}: C \rightarrow H$ is a family of mappings, $\lambda_{l} \geq 0, l \in\{1,2, \ldots, M\}$. The set of solution of (3) is denoted by $\operatorname{GSVI}\left(C, A_{l}\right)$. In particular, if $M=2, A_{1}=B, A_{2}=A, \lambda_{1}=\mu, \lambda_{2}=\lambda, x_{1}^{*}=x^{*}$, and $x_{2}^{*}=\gamma^{*}$, then the problem (3) is reduced to the problem (1).

Recall that a mapping $T: C \rightarrow C$ is said to be a $k$-strict pseudo-contraction (see also [4]) if there exists $0 \leq k<1$ such that

$$
\|T x-T y\|^{2} \leq\|x-y\|^{2}+k\|(I-T) x-(I-T) y\|^{2}, \forall x, y \in C,
$$

where $I$ denotes the identity operator on $C$ (see also [5]). If $k=0$, a mapping $T: C$ $\rightarrow C$ is said to be nonexpansive [6], that is,

$$
\|T x-T y\| \leq\|x-y\|, \quad \forall x, y \in C .
$$

If $k=1$, a mapping $T: C \rightarrow C$ is said to be pseudo-contraction, that is,

$$
\|T x-T y\|^{2} \leq\|x-y\|^{2}+\|(I-T) x-(I-T) y\|^{2}, \forall x, y \in C .
$$

Clearly, the class of $k$-strict pseudo-contraction falls into the one between classes of nonexpansive mappings and pseudo-contraction mappings. We denote the set of fixed points of $T$ by $F(T)$.

Let $\mathfrak{I}=\left\{F_{k}\right\}_{k \in \Gamma}$ be a countable family of bifunctions from $C \times C$ to $\mathbb{R}$, where $\mathbb{R}$ is the set of real numbers and $\Gamma$ is an arbitrary index set. Let $\phi: C \rightarrow \mathbb{R} \cup\{+\infty\}$ be a proper extended real-valued function. The system of mixed equilibrium problems is to find $x \in C$ such that

$$
F_{k}(x, y)+\varphi(\gamma) \geq \varphi(x), \quad \forall k \in \Gamma, \quad \forall k \in C .
$$

The set of solutions of (4) is denoted by $\operatorname{SMEP}\left(F_{k}, \phi\right)$, that is

$$
\operatorname{SMEP}\left(F_{k}, \varphi\right)=\left\{x \in C: F_{k}(x, y)+\varphi(y) \geq \varphi(x), \quad \forall k \in \Gamma, \forall y \in C\right\} .
$$

If $\Gamma$ is a singleton, the problem (4) reduces to find the following mixed equilibrium problem (see also Flores-Bazán [7]). For finding $x \in C$ such that

$$
F(x, y)+\varphi(y) \geq \varphi(x), \quad \forall y \in C .
$$

The set of solutions of (6) is denoted by $\operatorname{MEP}(F, \phi)$. Combettes and Hirstoaga [8] introduced the following system of equilibrium problems. For finding $x \in C$ such that,

$$
F_{k}(x, y) \geq 0, \forall k \in \Gamma, \forall y \in C .
$$


The set of solutions of (7) is denoted by $\operatorname{SEP}(\mathfrak{T})$, that is,

$$
\operatorname{SEP}(\Im)=\left\{x \in C: F_{k}(x, y) \geq 0, \forall k \in \Gamma, \forall y \in C\right\} .
$$

If $\Gamma$ is a singleton, the problem (7) becomes the following equilibrium problem. For finding $x \in C$ such that

$$
F(x, y) \geq 0, \forall y \in C .
$$

The set of solution of (9) is denoted by $E P(F)$. The mixed equilibrium problems include fixed point problems, variational inequality problems, optimization problems, Nash equilibrium problems, noncooperative games, economics and the equilibrium problem as special cases (see [9-19]). In the last two decades, many articles have appeared in the literature on the existence of solutions of equilibrium problems; see, for example [13] and references therein. Some solution methods have been proposed to solve the mixed equilibrium problems; see, for example, (see [11-14,16-24]) and references therein.

A family $\mathcal{S}=\{S(s): 0 \leq s<\infty\}$ of mappings of $C$ into itself is called a nonexpansive semigroup on $C$ if it satisfies the following conditions:

(i) $S(0) x=x$ for all $x \in C$;

(ii) $S(s+t)=S(s) S(t)$ for all $s, t \geq 0$;

(iii) $\|S(s) x-S(s) y\| \leq\|x-y\|$ for all $x, y \in C$ and $s \geq 0$;

(iv) for all $x \in C, s \mapsto S(s) x$ is continuous.

We denote by $F(\mathcal{S})$ the set of all common fixed points of $\mathcal{S}=\{S(s): s \geq 0\}$, i.e., $F(\mathcal{S})=\cap_{s \geq 0} F(S(s))$. It is well known that $F(\mathcal{S})$ is closed and convex (see also [25,26]).

In 2011, Shehu [21] introduced a new iterative scheme by hybrid method for finding a common element of the set of common fixed points of an infinite family of $k$-strictly pseudocontractive mappings and the set of common solutions to a system of generalized mixed equilibrium problems and the set of solution of variational inequality problems in Hilbert spaces. Starting with an arbitrary $x_{0} \in C, C_{1, i}=C, C_{1}=\cap_{i=1}^{\infty} C_{1, i}, x_{1}=P_{C_{1}} x_{0}$ define sequences $\left\{x_{n}\right\},\left\{w_{n}\right\},\left\{u_{n}\right\},\left\{z_{n}\right\}$, and $\left\{y_{n}\right.$, i) as follows:

$$
\left\{\begin{array}{l}
z_{n}=T_{r_{n}}^{\left(F_{1}, \varphi_{1}\right)}\left(x_{n}-r_{n} A x_{n}\right) \\
y_{n}=T_{\left.\lambda_{n}, \varphi_{2}\right)}^{\left(F_{2}\right.}\left(z_{n}-\lambda_{n} B z_{n}\right) \\
w_{n}=P_{C}\left(u_{n}-s_{n} D u_{n}\right) \\
y_{n, i}=\alpha_{n, i} w_{n}+\left(1-\alpha_{n, i}\right) T_{i} w_{n}, \quad n \geq 1, \\
C_{n+1, i}=\left\{z \in C_{n, i}:\left\|y_{n, i}-z\right\| \leq\left\|x_{n}-z\right\|\right\}, \quad n \geq 1, \\
C_{n+1}=\cap_{i=1}^{\infty} C_{n+1, i} \\
x_{n+1}=P_{C_{n+1}} x_{0}, \quad n \geq 1,
\end{array}\right.
$$

where $T_{i}$ be a $k_{i}$-strictly pseudocontractive mapping and for some $0 \leq k_{i}<1, A, B$ are $\alpha, \beta$-inverse-strongly monotone mappings of $C$ into $H$, respectively. He proved that if the sequences $\left\{\alpha_{n, i}\right\},\left\{r_{n}\right\},\left\{s_{n}\right\}$, and $\left\{\lambda_{n}\right\}$ of parameters satisfies appropriate conditions, then $\left\{x_{n}\right\}$ is generated by (10) converges strongly to $P_{\Omega} x_{0}$, where $P_{\Omega}$ is metric projection on $H$ in to $\Omega:=\operatorname{MEP}\left(F_{1}, \varphi_{1}\right) \cap \operatorname{MEP}\left(F_{2}, \varphi_{2}\right) \cap V I(C, A) \cap\left(\cap_{i=1}^{\infty} F\left(T_{i}\right)\right)$. For using the hybrid method, we can see [27-29].

In this article, motivated by the above results, we present a new iterative algorithm for finding a common element of the set of solutions for a system of mixed 
equilibrium problems, the set of common solutions of general system of finite variational inequality problems, the set of solutions of fixed points for nonexpansive semigroup mappings and the set of common fixed points for an infinite family of strictly pseudo-contractive mappings in a real Hilbert space. Then, we prove strong convergence theorem under some mind conditions. The results presented in this article extend and improve the results of Shehu [21] and many authors.

\section{Preliminaries}

Let $H$ be a real Hilbert space with norm $\|\cdot\|$ and inner product $\langle\cdot, \cdot\rangle$, respectively. Let $C$ be a closed convex subset of $H$. The sequence $\left\{x_{n}\right\}$ is a sequence in $H, x_{n} \rightarrow x$ means $\left\{x_{n}\right\}$ converges weakly to $x$ and $x_{n} \rightarrow x$ means $\left\{x_{n}\right\}$ converges strongly to $x$. In a real Hilbert space $H$, we have

$$
\|x-y\|^{2}=\|x\|^{2}-\|y\|^{2}-2\langle x-y, y\rangle
$$

and

$$
\|\lambda x+(1-\lambda) y\|^{2}=\lambda\|x\|^{2}+(1-\lambda)\|y\|^{2}-\lambda(1-\lambda)\|x-y\|^{2}, \quad \forall x, y \in H,
$$

and $\lambda \in \mathbb{R}$. For every point $x \in H$, there exists a unique nearest point in $C$, denoted by $P_{C} x$, such that

$$
\left\|x-P_{C} x\right\| \leq\|x-y\|, \quad \forall y \in C .
$$

$P_{C}$ is called the metric projection of $H$ onto $C$. It is well known that $P_{C}$ is a nonexpansive mapping of $H$ onto $C$ and satisfies

$$
\left\langle x-y, P_{C} x-P_{C} y\right\rangle \geq\left\|P_{C} x-P_{C} y\right\|^{2}, \quad \forall x, y \in H .
$$

Moreover, $P_{C} x$ is characterized by the following properties: $P_{C} x \in C$ and

$$
\begin{aligned}
& \left\langle x-P_{C} x, y-P_{C} x\right\rangle \leq 0, \\
& \|x-y\|^{2} \geq\left\|x-P_{C} x\right\|^{2}+\left\|y-P_{C} x\right\|^{2}, \forall x \in H, y \in C .
\end{aligned}
$$

Recall that a mapping $A$ of $C$ into $H$ is called $\alpha$-inverse-strongly monotone if there exists a positive real number $\alpha$ such that

$$
\langle A x-A y, x-y\rangle \geq \alpha\|A x-A y\|^{2}, \quad \forall x, y \in C .
$$

It is obvious that any $\alpha$-inverse-strongly monotone mappings $A$ is $\left(\frac{1}{\alpha}\right)$-Lipschitz monotone and continuous mappings.

In order to prove our main results, we need the following Lemmas.

Lemma 2.1. [30]Let $V: C \rightarrow H$ be a k-strict pseudo-contraction, then

(1) the fixed point set $F(V)$ of $V$ is closed convex so that the projection $P_{F(V)}$ is well defined;

(2) define a mapping $T: C \rightarrow H$ by

$$
T x=t x+(1-t) V x, \quad \forall x \in C .
$$


If $t \in[k, 1)$, then $T$ is a nonexpansive mapping such that $F(V)=F(T)$.

A family of mappings $\left\{V_{i}: C \rightarrow H\right\}_{i=1}^{\infty}$ is called a family of uniformly $k$-strict pseudocontractions, if there exists a constant $k \in[0,1)$ such that

$$
\left\|V_{i} x-V_{i} y\right\|^{2} \leq\|x-y\|^{2}+k\left\|\left(1-V_{i}\right) x-\left(I-V_{i}\right) y\right\|^{2}, \quad \forall x, y \in C, \quad \forall i \geq 1 .
$$

Let $\left\{V_{i}: C \rightarrow C\right\}_{i=1}^{\infty}$ be a countable family of uniformly $k$-strict pseudo-contractions. Let $\left\{T_{i}: C \rightarrow C\right\}_{i=1}^{\infty}$ be the sequence of nonexpansive mappings defined by (18), i.e.,

$$
T_{i} x=t x+(1-t) V_{i} x, \forall x \in C, \quad \forall i \geq 1, \quad t \in[k, 1) .
$$

Let $\left\{T_{i}\right\}$ be a sequence of nonexpansive mappings of $C$ into itself defined by (19) and let $\left\{\mu_{i}\right\}$ be a sequence of nonnegative numbers in $[0,1]$. For each $n \geq 1$, define a mapping $W_{n}$ of $C$ into itself as follows:

$$
\begin{aligned}
U_{n, n+1} & =I, \\
U_{n, n} & =\mu_{n} T_{n} U_{n, n+1}+\left(1-\mu_{n}\right) I, \\
U_{n, n-1} & =\mu_{n-1} T_{n-1} U_{n, n}+\left(1-\mu_{n-1}\right) I, \\
& \vdots \\
U_{n, k} & =\mu_{k} T_{k} U_{n, k+1}+\left(1-\mu_{k}\right) I, \\
U_{n, k-1} & =\mu_{k-1} T_{k-1} U_{n, k}+\left(1-\mu_{k-1}\right) I, \\
& \vdots \\
U_{n, 2} & =\mu_{2} T_{2} U_{n, 3}+\left(1-\mu_{2}\right) I, \\
W_{n}=U_{n, 1} & =\mu_{1} T_{1} U_{n, 2}+\left(1-\mu_{1}\right) I .
\end{aligned}
$$

Such a mapping $W_{n}$ is nonexpansive from $C$ to $C$ and it is called the $W$-mapping generated by $T_{1}, T_{2}, \ldots, T_{n}$ and $\mu_{1}, \mu_{2}, \ldots, \mu_{n}$.

For each $n, k \in \mathbb{N}$, let the mapping $U_{n, k}$ be defined by (20). Then we can have the following crucial conclusions concerning $W_{n}$. You can find them in [31]. Now we only need the following similar version in Hilbert spaces.

Lemma 2.2. [31] Let $C$ be a nonempty closed convex subset of a real Hilbert space $H$. Let $T_{1}, T_{2}, \ldots$ be nonexpansive mappings of $C$ into itself such that $\cap_{n=1}^{\infty} F\left(T_{n}\right)$ is nonempty, let $\mu_{1}, \mu_{2}, \ldots$ be real numbers such that $0 \leq \mu_{n} \leq b<1$ for every $n \geq 1$. Then,

(1) $W_{n}$ is nonexpansive and $F\left(W_{n}\right)=\cap_{i=1}^{n} F\left(T_{i}\right), \forall n \geq 1$;

(2) for every $x \in C$ and $k \in \mathbb{N}$, the limit $\lim _{n \rightarrow \infty} U_{n, k} x$ exists;

(3) a mapping $W: C \rightarrow C$ defined by

$$
W x:=\lim _{n \rightarrow \infty} W_{n} x=\lim _{n \rightarrow \infty} U_{n, 1} x, \forall x \in C
$$

is a nonexpansive mapping satisfying $F(W)=\cap_{i=1}^{\infty} F\left(T_{i}\right)$ and it is called the W-mapping generated by $T_{1}, T_{2}, \ldots$ and $\mu_{1}, \mu_{2}, \ldots$.

Lemma 2.3. [32] Let $C$ be a nonempty closed convex subset of a Hilbert space $H,\left\{T_{i}\right.$ : $C \rightarrow C\}$ be a countable family of nonexpansive mappings with $\cap_{i=1}^{\infty} F\left(T_{i}\right) \neq \emptyset,\left\{\mu_{i}\right\}$ be a real sequence such that $0<\mu_{i} \leq b<1, \forall i \geq 1$. If $D$ is any bounded subset of $C$, then

$$
\lim _{n \rightarrow \infty} \sup _{x \in D}\left\|W x-W_{n} x\right\|=0 .
$$


Lemma 2.4. [33]Each Hilbert space H satisfies Opial's condition, i.e., for any sequence $\left\{x_{n}\right\} \subset H$ with $x_{n} \rightarrow x$, the inequality

$$
\liminf _{n \rightarrow \infty}\left\|x_{n}-x\right\|<\liminf _{n \rightarrow \infty}\left\|x_{n}-y\right\|,
$$

hold for each $y \in H$ with $y \neq x$.

Lemma 2.5. [22]Let $C$ be a nonempty bounded closed convex subset of a Hilbert space $H$ and let $\mathcal{S}=\{S(s): 0 \leq s<\infty\}$ be a nonexpansive semigroup on $C$, then for any $h \geq 0$,

$$
\lim _{t \rightarrow \infty} \sup _{x \in C}\left\|\frac{1}{t} \int_{0}^{t} S(s) x d s-S(h)\left(\frac{1}{t} \int_{0}^{t} S(s) x d s\right)\right\|=0 .
$$

Lemma 2.6. [34] Let $C$ be a nonempty bounded closed convex subset of $H,\left\{x_{n}\right\}$ be a sequence in $C$ and $\mathcal{S}=\{S(s): 0 \leq s<\infty\}$ be a nonexpansive semigroup on $C$. If the following conditions are satisfied:

(i) $x_{n} \rightarrow z$;

(ii) $\lim \sup _{s \rightarrow \infty} \lim \sup _{n \rightarrow \infty}\left\|S(s) x_{n}-x_{n}\right\|=0$, then $z \in F(\mathcal{S})$.

Lemma 2.7. Let $C$ be a nonempty closed convex subset of Hilbert space $H, A_{l}: C \rightarrow$ $H$ be a $\beta_{l}$-inverse-strongly monotone and $\lambda_{l} \in\left(0,2 \beta_{l}\right)$ where $l \in\{1,2, \ldots, M\}$. If $\mathcal{P}: C \rightarrow C$ is defined by

$$
\mathcal{P}(x)=P_{C}\left(I-\lambda_{M} A_{M}\right) P_{C}\left(I-\lambda_{M-1} A_{M-1}\right) \ldots P_{C}\left(I-\lambda_{2} A_{2}\right) P_{C}\left(I-\lambda_{1} A_{1}\right) x, \forall x \in C,
$$

then $\mathcal{P}$ is nonexpansive.

Proof.

$\mathcal{P}_{C}^{l}=P_{C}\left(I-\lambda_{l} A_{l}\right) P_{C}\left(I-\lambda_{l-1} A_{l-1}\right) \ldots P_{C}\left(I-\lambda_{2} A_{2}\right) P_{C}\left(I-\lambda_{1} A_{1}\right), l \in\{1,2,3, \ldots, M\}$ and $\mathcal{P}_{C}^{0}=I$, where $I$ is the identity mapping on $H$. Then we have $\mathcal{P}=\mathcal{P}_{C}^{M}$.

For any $x, y \in C$, we have

$$
\begin{aligned}
\|\mathcal{P}(x)-\mathcal{P}(y)\| & =\left\|\mathcal{P}_{C}^{M} x-\mathcal{P}_{C}^{M} y\right\| \\
& =\left\|P_{C}\left(I-\lambda_{M} A_{M}\right) \mathcal{P}_{C}^{M-1} x-P_{C}\left(I-\lambda_{M} A_{M}\right) \mathcal{P}_{C}^{M-1} y\right\| \\
& \leq\left\|\left(I-\lambda_{M} A_{M}\right) \mathcal{P}_{C}^{M-1} x-\left(I-\lambda_{M} A_{M}\right) \mathcal{P}_{C}^{M-1} y\right\| \\
& \leq\left\|\mathcal{P}_{C}^{M-1} x-\mathcal{P}_{C}^{M-1} y\right\| \\
& \vdots \\
& \leq\left\|\mathcal{P}_{C}^{0} x-\mathcal{P}_{C}^{0} y\right\| \\
& =\|x-y\| .
\end{aligned}
$$

This show that $\mathcal{P}$ is nonexpansive on $C$.

Lemma 2.8. Let $C$ be a nonempty closed and convex subset of a real Hilbert space $H$, $A_{l}: C \rightarrow H$ be nonlinear mappings, where $l \in\{1,2, \ldots, M\}$. For $x_{l}^{*} \in C, l \in\{1,2, \ldots, M\}$, then $\left(x_{1}^{*}, x_{2}^{*}, \ldots, x_{M}^{*}\right)$ is a solution of problem (3) if and only if

$$
\left\{\begin{array}{l}
x_{1}^{*}=P_{C}\left(I-\lambda_{M} A_{M}\right) x_{M}^{*} \\
x_{2}^{*}=P_{C}\left(I-\lambda_{1} A_{1}\right) x_{1}^{*} \\
x_{3}^{*}=P_{C}\left(I-\lambda_{2} A_{2}\right) x_{2}^{*} \\
\vdots \\
x_{M}^{*}=P_{C}\left(I-\lambda_{M-1} A_{M-1}\right) x_{M-1}^{*},
\end{array}\right.
$$


that is

$$
x_{1}^{*}=P_{C}\left(I-\lambda_{M} A_{M}\right) P_{C}\left(I-\lambda_{M-1} A_{M-1}\right) \ldots P_{C}\left(I-\lambda_{2} A_{2}\right) P_{C}\left(I-\lambda_{1} A_{1}\right) x_{1}^{*} .
$$

Proof. From the problem (3), we can rewrite as

$$
\left\{\begin{array}{l}
\left\langle\begin{array}{l}
\left.x_{1}^{*}-\left(x_{M}^{*}-\lambda_{M} A_{M} x_{M}^{*}\right), x-x_{1}^{*}\right\rangle \geq 0, \forall x \in C, \\
\left.x_{M}^{*}-\left(x_{M-1}^{*}-\lambda_{M-1} A_{M-1} x_{M-1}^{*}\right), x-x_{M}^{*}\right\rangle \geq 0, \forall x \in C, \\
\vdots
\end{array}\right. \\
\left\langle\begin{array}{l}
x_{3}^{*}-\left(x_{2}^{*}-\lambda_{2} A_{2} x_{2}^{*}\right), x-x_{3}^{*} \\
\left.x_{2}^{*}-\left(x_{1}^{*}-\lambda_{1} A_{1} x_{1}^{*}\right), x-x_{2}^{*}\right\rangle \geq 0, \forall x \in C,
\end{array}\right.
\end{array}\right.
$$

From (15), we conclude that (23) is equivalent to (22).

Lemma 2.9. (Demi-closedness Principle [6]) Assume that $S$ is a nonexpansive selfmapping of a nonempty closed convex subset $C$ of a real Hilbert space H. If $S$ has a fixed point, the $I-S$ is demi-closed: that is, whenever $\left\{x_{n}\right\}$ is a sequence in $C$ converging weakly to some $x \in C$ (for short, $\left.x_{n}-x\right)$, and the sequence $\left\{(I-S) x_{n}\right\}$ converges strongly to some $y$ (for short, $(I-S) x_{n} \rightarrow y$ ), it follows that $(I-S) x=y$. Here $I$ is the identity operator of $H$.

For solving the system of mixed equilibrium problems, let us assume that bifunction $F_{k}: C \times C \rightarrow \mathbb{R}, k=1,2, \ldots, N$ satisfies the following conditions:

(H1) $F_{k}$ is monotone, i.e., $F_{k}(x, y)+F_{k}(y, x) \leq 0, \forall x, y \in C$;

(H2) for each fixed $y \in C, x \mapsto F_{k}(x, y)$ is convex and upper semicontinuous;

(H3) for each fixed $x \in C, y \mapsto F_{k}(x, y)$ is convex.

Lemma 2.10. [35] Let $C$ be a nonempty closed convex subset of a real Hilbert space $H$ and let $\phi$ be a lower semicontinuous and convex functional from $C$ to $\mathbb{R}$. Let $F$ be a bifunction from $C \times C$ to $\mathbb{R}$ satisfying (H1)-(H3). Assume that

(i) $\eta: C \times C \rightarrow H$ is $k$ Lipschitz continuous with constant $k>0$ such that;

(a) $\eta(x, y)+\eta(y, x)=0, \forall x, y \in C$,

(b) $\eta(\cdot, \cdot)$ is affine in the first variable,

(c) for each fixed $x \in C, y \mapsto \eta(x, y)$ is sequentially continuous from the weak topology to the weak topology,

(ii) $\mathcal{K}: C \rightarrow \mathcal{R}$ is $\eta$-strongly convex with constant $\sigma>0$ and its derivative $\mathcal{K}^{\prime}$ is sequentially continuous from the weak topology to the strong topology;

(iii) for each $x \in C$, there exist a bounded subset $D_{x} \subset C$ and $z_{x} \in C$ such that for any $y \in C \backslash D_{x}$,

$$
F\left(y, z_{x}\right)+\varphi\left(z_{x}\right)-\varphi(y)+\frac{1}{r}\left\langle\mathcal{K}^{\prime}(y)-\mathcal{K}^{\prime}(x), \eta\left(z_{x}, y\right)\right\rangle<0 .
$$

For given $r>0$, Let $K_{r}^{F}: C \rightarrow C$ be the mapping defined by:

$$
K_{r}^{F}(x)=\left\{y \in C: F(y, z)+\varphi(z)-\varphi(y)+\frac{1}{r}\left\langle\mathcal{K}^{\prime}(y)-\mathcal{K}^{\prime}(x), \eta(z, y)\right\rangle \geq 0, \forall z \in C\right\}
$$

for all $x \in C$. Then the following hold

(1) $K_{r}^{F}$ is single-valued; 
(2) $K_{r}^{F}$ is nonexpansive if $\mathcal{K}^{\prime}$ is Lipschitz continuous with constant $v>0$ such that $\sigma \geq k v$;

(3) $F\left(K_{r}^{F}\right)=\operatorname{MEP}(F, \varphi)$;

(4) $\operatorname{MEP}(F, \phi)$ is closed and convex.

\section{Main result}

In this section, we prove a strong convergence theorem in a real Hilbert space.

Theorem 3.1. Let $C$ be a nonempty closed convex subset of a real Hilbert Space $H$. Let $\left\{F_{k}: C \times C \rightarrow \mathbb{R}, k=1,2, \ldots, N\right\}$ be a finite family of bifunctions satisfying conditions (H1)-(H3). Let $A_{l}$ be $\beta_{l}$-inverse-strongly monotone mappings of $C$ into $H$, where $l \in$ $\{1,2, \ldots, M\}$. Let $\mathcal{S}=\{S(s): 0 \leq s<\infty\}$ be a nonexpansive semigroup on $C$ and let $\left\{t_{n}\right\}$ be a positive real divergent sequence. Let $\left\{V_{i}: C \rightarrow C\right\}_{i=1}^{\infty}$ be a countable family of uniformly $k$-strict pseudo-contractions, $\left\{T_{i}: C \rightarrow C\right\}_{i=1}^{\infty}$ be a countable family of nonexpansive mappings defined by $T_{i} x=t x+(1-t) V_{i} x, \forall x \in C, \forall i \geq 1, t \in[k, 1)$. For $l \in\{1,2$, ..., $M\}$, suppose $\Theta:=F(\mathcal{S}) \cap\left(\cap_{i=1}^{\infty} F\left(T_{i}\right)\right) \cap\left(\cap_{k=1}^{N} \operatorname{SMEP}\left(F_{k}\right)\right) \cap \operatorname{GSVI}\left(C, A_{l}\right) \neq \emptyset$. Let $\left\{x_{n}\right\}$ be a sequence generated by $x_{0} \in C, C_{1, i}=C, C_{1}=\cap_{i=1}^{\infty} C_{1, i}, x_{1}=P_{C_{1}} x_{0}$ and

$$
\left\{\begin{array}{l}
u_{n}=K_{r_{N, n}}^{F_{N}} K_{r_{N-1, n}}^{F_{N-1}} \ldots K_{r_{2, n}}^{F_{2}} K_{r_{1, n}}^{F_{1}} x_{n}, \\
w_{n}=P_{C}\left(I-\lambda_{M} A_{M}\right) P_{C}\left(I-\lambda_{M-1} A_{M-1}\right) \ldots P_{C}\left(I-\lambda_{2} A_{2}\right) P_{C}\left(I-\lambda_{1} A_{1}\right) u_{n}, \\
y_{n, i}=\alpha_{n, i} x_{0}+\left(1-\alpha_{n, i}\right) \frac{1}{t_{n}} \int_{0}^{t_{n}} S(s) W_{n} w_{n} d s \\
C_{n+1, i}=\left\{z \in C_{n, i}:\left\|y_{n, i}-z\right\|^{2} \leq\left\|x_{n}-z\right\|^{2}+\alpha_{n, i}\left(\left\|x_{0}\right\|^{2}+2\left\langle x_{n}-x_{0}, z\right\rangle\right)\right\} \\
C_{n+1}=\cap_{i=1}^{\infty} C_{n+1, i} \\
x_{n+1}=P_{C_{n+1}} x_{0}
\end{array}\right.
$$

for every $n \geq 0$, where $K_{r_{k}}^{F_{k}}: C \rightarrow C$, is the mapping defined by (24), $r_{k}>0, k=1,2$, ..., $N$ are constants and $\left\{\alpha_{n, i}\right\}_{n=1}^{\infty} \subset(0,1)$ satisfy the following conditions:

(i) $\eta_{k}: C \times C \rightarrow H$ is $L_{k}$-Lipschitz continuous with constant $k=1,2, \ldots, N$ such that

(1) $\eta_{k}(x, y)+\eta_{k}(y, x)=0, \forall x, y \in C$,

(2) $x \mapsto \eta_{k}(x, y)$ is affine,

(3) for each fixed $y \in C, y \mapsto \eta_{k}(x, y)$ is sequentially continuous from the weak topology to the weak topology;

(ii) $\mathcal{K}_{k}: C \rightarrow \mathcal{R}$ is $\eta_{k}$-strongly convex with constant $\sigma_{k}>0$ and its derivative $\mathcal{K}_{k}^{\prime}$ is not only sequentially continuous from the weak topology to the strong topology but also Lipschitz continuous with a Lipschitz constant $v_{k}>0$ such that $\sigma_{k}>L_{k} v_{k}$;

(iii) For each $k \in\{1,2, \ldots, N\}$ and for all $x \in C$, there exist a bounded subset $D_{x} \subset$ $C$ and $z_{x} \in C$ such that for any $y \in C \backslash D_{x}$,

$$
F_{k}\left(\gamma, z_{x}\right)+\varphi\left(z_{x}\right)-\varphi(y)+\frac{1}{r_{k}}\left\langle\mathcal{K}^{\prime}(y)-\mathcal{K}^{\prime}(x), \eta\left(z_{x}, y\right)\right\rangle<0
$$

(iv) $\lim _{n \rightarrow \infty} \alpha_{n, i}=0, \forall i \geq 1$;

(v) $\left\{\lambda_{l}\right\} \subset\left(0,2 \beta_{l}\right), \forall l=1,2, \ldots, M$;

(vi) $\lim \inf _{n \rightarrow \infty} r_{k, n}>0, \forall k=1,2,3, \ldots, N$. 
Then, $\left\{x_{n}\right\}$ converges strongly to $P_{\Theta} x_{0}$.

Proof. First, we show that $I-\lambda_{l} A_{l}$ for all $l \in\{1,2, \ldots, M\}$ is nonexpansive mappings. Indeed, for all $x, y \in C$ and $\lambda_{l} \in\left(0,2 \beta_{l}\right)$, we observe that

$$
\begin{aligned}
\left\|\left(I-\lambda_{1} A_{l}\right) x-\left(I-\lambda_{1} A_{l}\right) y\right\|^{2} & =\left\|x-y-\lambda_{l}\left(A_{l} x-A_{l} y\right)\right\|^{2} \\
& =\|x-y\|^{2}-2 \lambda_{l}\left\langle x-y, A_{l} x-A_{l} y\right\rangle+\lambda_{l}^{2}\left\|A_{l} x-A_{l} y\right\|^{2} \\
& \leq\|x-y\|^{2}-2 \lambda_{1} \beta_{l}\left\|A_{l} x-A_{l} y\right\|^{2}+\lambda_{l}^{2}\left\|A_{l} x-A_{l} y\right\|^{2} \\
& \leq\|x-y\|^{2}+\lambda_{l}\left(\lambda_{l}-2 \beta_{l}\right)\left\|A_{l} x-A_{l} y\right\|^{2} \\
& \leq\|x-y\|^{2},
\end{aligned}
$$

which implies that the mapping $I-\lambda_{l} A_{l}$ is nonexpansive for all $l \in\{1,2, \ldots, M\}$.

Let $p \in \Theta$. Taking

$$
\Im_{n}^{k}=K_{r_{k, n}}^{F_{k}} K_{r_{k-1, n}}^{F_{k-1}} \ldots K_{r_{2, n}}^{F_{2}} K_{r_{1, n}}^{F_{1}}, k \in\{1,2,3, \ldots, N\}, n \in \mathbb{N}
$$

and

$$
\mathcal{P}_{C}^{l}=P_{C}\left(I-\lambda_{l} A_{l}\right) P_{C}\left(I-\lambda_{l-1} A_{l-1}\right) \ldots P_{C}\left(I-\lambda_{2} A_{2}\right) P_{C}\left(I-\lambda_{1} A_{1}\right) \text { for all } l \in\{1,2,3, \ldots, M\},
$$

$\Im_{n}^{0}=\mathcal{P}_{C}^{0}=I$, where $I$ is the identity mapping on $H$. From the definition of $K_{r_{k, n}}^{F_{k}}$ and $P_{C}$ are nonexpansive then $\Im_{n^{\prime}}^{k}, k \in\{1,2,3, \ldots, N\}$ and $\mathcal{P}_{C^{\prime}}^{l} l \in\{1,2,3, \ldots, M\}$ also. We note that $u_{n}=\Im_{n}^{N} x_{n}$ and $p=\Im_{r_{k, n}}^{F_{k}} p$, we have

$$
\left\|u_{n}-p\right\|=\left\|\Im_{n}^{N} x_{n}-\Im_{n}^{N} p\right\| \leq\left\|x_{n}-p\right\| .
$$

It follows that

$$
\left\|w_{n}-p\right\|=\left\|\mathcal{P}_{C}^{l} u_{n}-\mathcal{P}_{C}^{l} p\right\| \leq\left\|u_{n}-p\right\| \leq\left\|x_{n}-p\right\|, \forall l \in\{1,2,3, \ldots, M\} .
$$

Next, we will divide the proof into five steps.

Step 1. We show that $\left\{x_{n}\right\}$ is well defined. Let $n=1$, then $C_{1, i}=C$ is closed and convex for each $i \geq 1$. Suppose that $C_{n, i}$ is closed convex for some $n>1$. Then, from definition of $C_{n+1, i}$, we know that $C_{n+1, i}$ is closed convex for the same $n \geq 1$. Hence, $C_{n, i}$ is closed convex for $n \geq 1$ and for each $i \geq 1$. This implies that $C_{n}$ is closed convex for $n$ $\geq 1$. Furthermore, we show that $\Theta \subset C_{n}$. For $n=1, \Theta \subset C=C_{1, i}$. For $n \geq 2$, let $p \in \Theta$. Then,

$$
\begin{aligned}
\left\|y_{n, i}-p\right\|^{2} & =\left\|\alpha_{n, i}\left(x_{0}-p\right)+\left(1-\alpha_{n, i}\right)\left(\frac{1}{t_{n}} \int_{0}^{t_{n}} S(s) W_{n} w_{n} d s-p\right)\right\|^{2} \\
& \leq \alpha_{n, i}\left\|x_{0}-p\right\|^{2}+\left(1-\alpha_{n, i}\right)\left\|\frac{1}{t_{n}} \int_{0}^{t_{n}} S(s) W_{n} w_{n} d s-p\right\|^{2} \\
& \leq \alpha_{n, i}\left\|x_{0}-p\right\|^{2}+\left(1-\alpha_{n, i}\right)\left\|w_{n}-p\right\|^{2} \\
& =\left\|w_{n}-p\right\|^{2}+\alpha_{n, i}\left(\left\|x_{0}-p\right\|^{2}-\left\|w_{n}-p\right\|^{2}\right) \\
& \leq\left\|x_{n}-p\right\|^{2}+\alpha_{n, i}\left(\left\|x_{0}\right\|^{2}+2\left\langle x_{n}-x_{0}, p\right\rangle\right),
\end{aligned}
$$

which shows that $p \in C_{n, i}, \forall n \geq 2, \forall i \geq 1$. Thus, $\Theta \subset C_{n, i}, \forall n \geq 1, \forall i \geq 1$. Hence, it follows that $\emptyset \neq \Theta \subset C_{n}, \forall n \geq 1$. This implies that $\left\{x_{n}\right\}$ is well-defined. 
Step 2. We claim that $\lim _{n \rightarrow \infty}\left\|x_{n+1}-x_{n}\right\|=0$ and $\lim _{n \rightarrow \infty}\left\|y_{n, i}-x_{n}\right\|=0$, for $i \geq 1$. Since $x_{n}=P_{C_{n}} x_{0}$ and $x_{n+1}=P_{C_{n+1}} x_{0} \in C_{n+1} \subset C_{n}, \forall n \geq 1$, we have

$$
\left\|x_{n}-x_{0}\right\| \leq\left\|x_{n+1}-x_{0}\right\| .
$$

Also, as $\Theta \subset C_{n}$ by (13), it follows that

$$
\left\|x_{n}-x_{0}\right\| \leq\left\|z-x_{0}\right\|, z \in \Theta, \forall n \geq 1 .
$$

Form (30) and (31), we have that $\lim _{n \rightarrow \infty}\left\|x_{n}-x_{0}\right\|$ exists. Hence $\left\{x_{n}\right\}$ is bounded and so are $\left\{y_{n, i}\right\}, \forall i \geq 1,\left\{w_{n}\right\},\left\{u_{n}\right\},\left\{W_{n} w_{n}\right\}$, and $\left\{\frac{1}{t_{n}} \int_{0}^{t_{n}} S(s) W_{n} w_{n} d s\right\}$. For $m>n \geq 1$, we have that $x_{m}=P_{C_{m}} x_{0} \in C_{m} \subset C_{n}$. By (16), we obtain

$$
\left\|x_{m}-x_{n}\right\|^{2} \leq\left\|x_{n}-x_{0}\right\|^{2}-\left\|x_{m}-x_{0}\right\|^{2} .
$$

Letting $m, n \rightarrow \infty$ and taking the limit in (32), we have $\left\|x_{m}-x_{n}\right\| \rightarrow 0$, which shows that $\left\{x_{n}\right\}$ is a Cauchy sequence. In particular,

$$
\lim _{n \rightarrow \infty}\left\|x_{n+1}-x_{n}\right\|=0 .
$$

Since, $\left\{x_{n}\right\}$ is a Cauchy sequence, we assume that $x_{n} \rightarrow z \in C$. Since $x_{n+1}=P_{C_{n+1}} x_{0} \in C_{n+1}$, then for each $i \geq 1$,

$$
\left\|y_{n, i}-x_{n+1}\right\|^{2} \leq\left\|x_{n}-x_{n+1}\right\|^{2}+\alpha_{n, i}\left(\left\|x_{0}\right\|^{2}+2\left\langle x_{n}-x_{0}, x_{n+1}\right\rangle\right) \rightarrow 0, n \rightarrow \infty .
$$

It follows that

$$
\left\|y_{n, i}-x_{n}\right\| \leq\left\|y_{n, i}-x_{n+1}\right\|+\left\|x_{n+1}-x_{n}\right\| .
$$

Therefore

$$
\lim _{n \rightarrow \infty}\left\|y_{n, i}-x_{n}\right\|=0, \forall i \geq 1
$$

Step 3. We claim that the following statements hold:

(1) $\lim _{n \rightarrow \infty}\left\|\Im_{n}^{k} x_{n}-\Im_{n}^{k-1} x_{n}\right\|=0, \forall k=1,2, \ldots, N$;

(2) $\lim _{n \rightarrow \infty}\left\|u_{n}-x_{n}\right\|=0$;

(3) $\lim _{n \rightarrow \infty}\left\|u_{n}-w_{n}\right\|=0$.

Indeed, for $p \in \Theta$, note that $K_{r_{k, n}}^{F_{k}}, k=1,2, \ldots, N$ is the firmly nonexpansive, so we have

$$
\begin{aligned}
\left\|\Im_{n}^{k} x_{n}-\Im_{n}^{k} p\right\|^{2} & =\left\|K_{r_{k}, n}^{F_{k}} \Im_{n}^{k-1} x_{n}-K_{r_{k, n}}^{F_{k}} p\right\|^{2} \\
& \leq\left\langle\Im_{n}^{k} x_{n}-p, \Im_{n}^{k-1} x_{n}-p\right\rangle \\
& =\frac{1}{2}\left\{\left\|\Im_{n}^{k} x_{n}-p\right\|^{2}+\left\|\Im_{n}^{k-1} x_{n}-p\right\|^{2}-\left\|\Im_{n}^{k} x_{n}-\Im_{n}^{k-1} x_{n}\right\|^{2}\right\} .
\end{aligned}
$$

Thus, we get

$$
\left\|\Im_{n}^{k} x_{n}-\Im_{n}^{k} p\right\|^{2} \leq\left\|\Im_{n}^{k-1} x_{n}-p\right\|^{2}-\left\|\Im_{n}^{k} x_{n}-\Im_{n}^{k-1} x_{n}\right\|^{2} .
$$


It follows that

$$
\begin{aligned}
\left\|u_{n}-p\right\|^{2} & \leq\left\|\Im_{n}^{k} x_{n}-\Im_{n}^{k} p\right\|^{2} \\
& \leq\left\|\Im_{n}^{k-1} x_{n}-p\right\|^{2}-\left\|\Im_{n}^{k} x_{n}-\Im_{n}^{k-1} x_{n}\right\|^{2} \\
& \leq\left\|x_{n}-p\right\|^{2}-\left\|\Im_{n}^{k} x_{n}-\Im_{n}^{k-1} x_{n}\right\|^{2} .
\end{aligned}
$$

From (29) and (35), we have for $i \geq 1$,

$$
\begin{aligned}
\left\|y_{n, i}-p\right\|^{2} & \leq \alpha_{n, i}\left\|x_{0}-p\right\|^{2}+\left(1-\alpha_{n, i}\right)\left\|w_{n}-p\right\|^{2} \\
& \leq \alpha_{n, i}\left\|x_{0}-p\right\|^{2}+\left(1-\alpha_{n, i}\right)\left\|u_{n}-p\right\|^{2} \\
& \leq \alpha_{n, i}\left\|x_{0}-p\right\|^{2}+\left(1-\alpha_{n, i}\right)\left[\left\|x_{n}-p\right\|^{2}-\left\|\Im_{n}^{k} x_{n}-\Im_{n}^{k-1} x_{n}\right\|^{2}\right]
\end{aligned}
$$

it follows that

$$
\begin{aligned}
\left(1-\alpha_{n, i}\right)\left\|\Im_{n}^{k} x_{n}-\Im_{n}^{k-1} x_{n}\right\|^{2} & \leq \alpha_{n, i}\left\|x_{0}-p\right\|^{2}+\left\|x_{n}-p\right\|^{2}-\left\|y_{n, i}-p\right\|^{2} \\
& \leq \alpha_{n, i}\left\|x_{0}-p\right\|^{2}+\left\|x_{n}-y_{n, i}\right\|\left(\left\|x_{n}-p\right\|+\left\|y_{n, i}-p\right\|\right) .
\end{aligned}
$$

By the condition (iv) and (34), we have

$$
\lim _{n \rightarrow \infty}\left\|\Im_{n}^{k} x_{n}-\Im_{n}^{k-1} x_{n}\right\|=0 .
$$

For $p \in \Theta$ and again since $K_{r_{k, n}}^{F_{k}}, k=1,2, \ldots, N$ is the firmly nonexpansive, we obtain

$$
\begin{aligned}
\left\|u_{n}-p\right\|^{2} & =\left\|\Im_{n}^{k} x_{n}-\Im_{n}^{k} p\right\|^{2} \\
& \leq\left\langle\Im_{n}^{k} x_{n}-\Im_{n}^{k} p, x_{n}-p\right\rangle \\
& =\frac{1}{2}\left\{\left\|\Im_{n}^{k} x_{n}-\Im_{n}^{k} p\right\|^{2}+\left\|x_{n}-p\right\|^{2}-\left\|\Im_{n}^{k} x_{n}-x_{n}\right\|^{2}\right\} \\
& =\frac{1}{2}\left\{\left\|u_{n}-p\right\|^{2}+\left\|x_{n}-p\right\|^{2}-\left\|u_{n}-x_{n}\right\|^{2}\right\}
\end{aligned}
$$

and hence

$$
\left\|u_{n}-p\right\|^{2} \leq\left\|x_{n}-p\right\|^{2}-\left\|u_{n}-x_{n}\right\|^{2}
$$

From (29) and (37), for $i \geq 1$, we have

$$
\begin{aligned}
\left\|y_{n, i}-p\right\|^{2} & \leq \alpha_{n, i}\left\|x_{0}-p\right\|^{2}+\left(1-\alpha_{n, i}\right)\left\|w_{n}-p\right\|^{2} \\
& \leq \alpha_{n, i}\left\|x_{0}-p\right\|^{2}+\left(1-\alpha_{n, i}\right)\left\|u_{n}-p\right\|^{2} \\
& \leq \alpha_{n, i}\left\|x_{0}-p\right\|^{2}+\left(1-\alpha_{n, i}\right)\left[\left\|x_{n}-p\right\|^{2}-\left\|u_{n}-x_{n}\right\|^{2}\right]
\end{aligned}
$$

it follows that

$$
\begin{aligned}
\left(1-\alpha_{n, i}\right)\left\|u_{n}-x_{n}\right\|^{2} & \leq \alpha_{n, i}\left\|x_{0}-p\right\|^{2}+\left\|x_{n}-p\right\|^{2}-\left\|y_{n, i}-p\right\|^{2} \\
& \leq \alpha_{n, i}\left\|x_{0}-p\right\|^{2}+\left\|x_{n}-y_{n, i}\right\|\left(\left\|x_{n}-p\right\|+\left\|y_{n, i}-p\right\|\right) .
\end{aligned}
$$


By the condition (iv) and (34), we have

$$
\lim _{n \rightarrow \infty}\left\|u_{n}-x_{n}\right\|=0 .
$$

From (26), we note that

$$
\begin{aligned}
\left\|w_{n}-p\right\|^{2} & =\left\|\mathcal{P}_{C}^{M} u_{n}-\mathcal{P}_{C}^{M} p\right\|^{2} \\
& =\left\|P_{C}\left(I-\lambda_{M} A_{M}\right) \mathcal{P}_{C}^{M-1} u_{n}-P_{C}\left(I-\lambda_{M} A_{M}\right) \mathcal{P}_{C}^{M-1} p\right\|^{2} \\
& \leq\left\|\left(I-\lambda_{M} A_{M}\right) \mathcal{P}_{C}^{M-1} u_{n}-\left(I-\lambda_{M} A_{M}\right) \mathcal{P}_{C}^{M-1} p\right\|^{2} \\
& \leq\left\|\mathcal{P}_{C}^{M-1} u_{n}-\mathcal{P}_{C}^{M-1} p\right\|^{2}+\lambda_{M}\left(\lambda_{M}-2 \beta_{M}\right)\left\|A_{M} \mathcal{P}_{C}^{M-1} u_{n}-A_{M} \mathcal{P}_{C}^{M-1} p\right\|^{2} \\
& \vdots \\
& \leq\left\|u_{n}-p\right\|^{2}+\sum_{l=1}^{M} \lambda_{l}\left(\lambda_{l}-2 \beta_{i}\right)\left\|A_{l} \mathcal{P}_{C}^{l-1} u_{n}-A_{l} \mathcal{P}_{C}^{l-1} p\right\|^{2} \\
& \leq\left\|x_{n}-p\right\|^{2}+\sum_{l=1}^{M} \lambda_{l}\left(\lambda_{l}-2 \beta_{l}\right)\left\|A_{l} \mathcal{P}_{C}^{l-1} u_{n}-A_{l} \mathcal{P}_{C}^{l-1} p\right\|^{2} .
\end{aligned}
$$

It follows that, for $i \geq 1$

$$
\begin{aligned}
\left\|y_{n, i}-p\right\|^{2} & \leq \alpha_{n, i}\left\|x_{0}-p\right\|^{2}+\left(1-\alpha_{n, i}\right)\left\|w_{n}-p\right\|^{2} \\
& =\alpha_{n, i}\left\|x_{0}-p\right\|^{2}+\left(1-\alpha_{n, i}\right)\left[\left\|x_{n}-p\right\|^{2}+\sum_{l=1}^{M} \lambda_{l}\left(\lambda_{l}-2 \beta_{l}\right)\left\|A_{l} \mathcal{P}_{C}^{l-1} u_{n}-A_{l} \mathcal{P}_{C}^{l-1} p\right\|^{2}\right] \\
& \leq \alpha_{n, i}\left\|x_{0}-p\right\|^{2}+\left\|x_{n}-p\right\|^{2}+\left(1-\alpha_{n, i}\right) \sum_{l=1}^{M} \lambda_{l}\left(\lambda_{l}-2 \beta_{l}\right)\left\|A_{l} \mathcal{P}_{C}^{l-1} u_{n}-A_{l} \mathcal{P}_{C}^{l-1} p\right\|^{2},
\end{aligned}
$$

which implies that

$$
\begin{aligned}
\left(1-\alpha_{n, i}\right) \sum_{l=1}^{M} & \lambda_{l}\left(2 \beta_{l}-\lambda_{l}\right)\left\|A_{l} \mathcal{P}_{C}^{l-1} u_{n}-A_{l} \mathcal{P}_{C}^{l-1} p\right\|^{2} \\
& =\alpha_{n, i}\left\|x_{0}-p\right\|^{2}+\left\|x_{n}-p\right\|^{2}-\left\|y_{n, i}-p\right\|^{2} \\
& \leq \alpha_{n, i}\left\|x_{0}-p\right\|^{2}+\left\|x_{n}-y_{n, i}\right\|\left(\left\|x_{n}-p\right\|+\left\|y_{n, i}-p\right\|\right) .
\end{aligned}
$$

By the conditions (iv), (v) and (34), we obtain

$$
\lim _{n \rightarrow \infty}\left\|A_{l} \mathcal{P}_{C}^{l-1} u_{n}-A_{l} \mathcal{P}_{C}^{l-1} p\right\|=0
$$

On the other hand, we note that

$$
\begin{aligned}
\left\|\mathcal{P}_{C}^{M} u_{n}-\mathcal{P}_{C}^{M} p\right\|^{2}= & \left\|P_{C}\left(I-\lambda_{M} A_{M}\right) \mathcal{P}_{C}^{M-1} u_{n}-P_{C}\left(I-\lambda_{M} A_{M}\right) \mathcal{P}_{C}^{M-1} p\right\|^{2} \\
\leq & \left\langle\left(I-\lambda_{M} A_{M}\right) \mathcal{P}_{C}^{M-1} u_{n}-\left(I-\lambda_{M} A_{M}\right) \mathcal{P}_{C}^{M-1} p, \mathcal{P}_{C}^{M} u_{n}-\mathcal{P}_{C}^{M} p\right\rangle \\
= & \frac{1}{2}\left\{\left\|\left(I-\lambda_{M} A_{M}\right) \mathcal{P}_{C}^{M-1} u_{n}-\left(I-\lambda_{M} A_{M}\right) \mathcal{P}_{C}^{M-1} p\right\|^{2}+\left\|\mathcal{P}_{C}^{M} u_{n}-\mathcal{P}_{C}^{M} p\right\|^{2}\right. \\
& \left.-\left\|\left(I-\lambda_{M} A_{M}\right) \mathcal{P}_{C}^{M-1} u_{n}-\left(I-\lambda_{M} A_{M}\right) \mathcal{P}_{C}^{M-1} p-\left(\mathcal{P}_{C}^{M} u_{n}-\mathcal{P}_{C}^{M} p\right)\right\|^{2}\right\} \\
\leq & \frac{1}{2}\left\{\left\|\mathcal{P}_{C}^{M-1} u_{n}-\mathcal{P}_{C}^{M-1} p\right\|^{2}+\left\|\mathcal{P}_{C}^{M} u_{n}-\mathcal{P}_{C}^{M} p\right\|^{2}\right. \\
& \left.-\left\|\left(\mathcal{P}_{C}^{M-1} u_{n}-\mathcal{P}_{C}^{M-1} p-\mathcal{P}_{C}^{M} u_{n}+\mathcal{P}_{C}^{M} p\right)-\lambda_{M}\left(A_{M} \mathcal{P}_{C}^{M-1} u_{n}-A_{M} \mathcal{P}_{C}^{M-1} p\right)\right\|^{2}\right\} \\
= & \frac{1}{2}\left\{\left\|\mathcal{P}_{C}^{M-1} u_{n}-\mathcal{P}_{C}^{M-1} p\right\|^{2}+\left\|\mathcal{P}_{C}^{M} u_{n}-\mathcal{P}_{C}^{M} p\right\|^{2}-\| \mathcal{P}_{C}^{M-1} u_{n}-\mathcal{P}_{C}^{M-1} p-\mathcal{P}_{C}^{M} u_{n}\right. \\
& +\mathcal{P}_{C}^{M} p \|^{2}+2 \lambda_{M}\left\langle\mathcal{P}_{C}^{M-1} u_{n}-\mathcal{P}_{C}^{M-1} p-\mathcal{P}_{C}^{M} u_{n}+\mathcal{P}_{C}^{M} p, A_{M} \mathcal{P}_{C}^{M-1} u_{n}-A_{M} \mathcal{P}_{C}^{M-1} p\right\rangle \\
& \left.-\lambda_{M}^{2}\left\|A_{M} \mathcal{P}_{C}^{M-1} u_{n}-A_{M} \mathcal{P}_{C}^{M-1} p\right\|^{2}\right\} \\
\leq & \frac{1}{2}\left\{\left\|\mathcal{P}_{C}^{M-1} u_{n}-\mathcal{P}_{C}^{M-1} p\right\|^{2}+\left\|\mathcal{P}_{C}^{M} u_{n}-\mathcal{P}_{C}^{M} p\right\|^{2}-\| \mathcal{P}_{C}^{M-1} u_{n}-\mathcal{P}_{C}^{M-1} p-\mathcal{P}_{C}^{M} u_{n}\right. \\
& \left.+\mathcal{P}_{C}^{M} p\left\|^{2}+2 \lambda_{M}\right\| \mathcal{P}_{C}^{M-1} u_{n}-\mathcal{P}_{C}^{M-1} p-\mathcal{P}_{C}^{M} u_{n}+\mathcal{P}_{C}^{M} p\|\| A_{M} \mathcal{P}_{C}^{M-1} u_{n}-A_{M} \mathcal{P}_{C}^{M-1} p \|\right\},
\end{aligned}
$$


which implies that

$$
\begin{aligned}
\left\|\mathcal{P}_{C}^{M} u_{n}-\mathcal{P}_{C}^{M} p\right\|^{2} \leq & \left\|\mathcal{P}_{C}^{M-1} u_{n}-\mathcal{P}_{C}^{M-1} p\right\|^{2}-\left\|\mathcal{P}_{C}^{M-1} u_{n}-\mathcal{P}_{C}^{M-1} p-\mathcal{P}_{C}^{M} u_{n}+\mathcal{P}_{C}^{M} p\right\|^{2} \\
& +2 \lambda_{M}\left\|\mathcal{P}_{C}^{M-1} u_{n}-\mathcal{P}_{C}^{M-1} p-\mathcal{P}_{C}^{M} u_{n}+\mathcal{P}_{C}^{M} p\right\|\left\|A_{M} \mathcal{P}_{C}^{M-1} u_{n}-A_{M} \mathcal{P}_{C}^{M-1} p\right\| \\
& \vdots \\
\leq & \left\|u_{n}-p\right\|^{2}-\sum_{l=1}^{M}\left\|\mathcal{P}_{C}^{l-1} u_{n}-\mathcal{P}_{C}^{l-1} p-\mathcal{P}_{C}^{l} u_{n}+\mathcal{P}_{C}^{l}\right\|^{2} \\
& +\sum_{l=1}^{M} 2 \lambda_{l}\left\|\mathcal{P}_{C}^{l-1} u_{n}-\mathcal{P}_{C}^{l-1} p-\mathcal{P}_{C}^{l} u_{n}+\mathcal{P}_{C}^{l} p\right\|\left\|A_{l} \mathcal{P}_{C}^{l-1} u_{n}-A_{l} \mathcal{P}_{C}^{l-1} p\right\| \\
\leq & \left\|x_{n}-p\right\|^{2}-\sum_{l=1}^{M}\left\|\mathcal{P}_{C}^{l-1} u_{n}-\mathcal{P}_{C}^{l-1} p-\mathcal{P}_{C}^{l} u_{n}+\mathcal{P}_{C}^{l} p\right\|^{2} \\
& +\sum_{l=1}^{M} 2 \lambda_{l}\left\|\mathcal{P}_{C}^{l-1} u_{n}-\mathcal{P}_{C}^{l-1} p-\mathcal{P}_{C}^{l} u_{n}+\mathcal{P}_{C}^{l} p\right\|\left\|A_{l} \mathcal{P}_{C}^{l-1} u_{n}-A_{l} \mathcal{P}_{C}^{l-1} p\right\| .
\end{aligned}
$$

From (29) and (43), for $i \geq 1$, we note that

$$
\begin{aligned}
\left\|y_{n, i}-p\right\|^{2} \leq & \alpha_{n, i}\left\|x_{0}-p\right\|^{2}+\left(1-\alpha_{n, i}\right)\left\|w_{n}-p\right\|^{2} \\
= & \alpha_{n, i}\left\|x_{0}-p\right\|^{2}+\left(1-\alpha_{n, i}\right)\left\|\mathcal{P}_{C}^{M} u_{n}-\mathcal{P}_{C}^{M} p\right\|^{2} \\
\leq & \alpha_{n, i}\left\|x_{0}-p\right\|^{2}+\left(1-\alpha_{n, i}\right)\left\{\left\|x_{n}-p\right\|^{2}-\sum_{l=1}^{M}\left\|\mathcal{P}_{C}^{l-1} u_{n}-\mathcal{P}_{C}^{l-1} p-\mathcal{P}_{C}^{l} u_{n}+\mathcal{P}_{C}^{l} p\right\|^{2}\right. \\
& \left.+\sum_{l=1}^{M} 2 \lambda_{l}\left\|\mathcal{P}_{C}^{l-1} u_{n}-\mathcal{P}_{C}^{l-1} p-\mathcal{P}_{C}^{l} u_{n}+\mathcal{P}_{C}^{l} p\right\|\left\|A_{l} \mathcal{P}_{C}^{l-1} u_{n}-A_{l} \mathcal{P}_{C}^{l-1} p\right\|\right\} \\
\leq & \alpha_{n, i}\left\|x_{0}-p\right\|^{2}+\left\|x_{n}-p\right\|^{2}-\left(1-\alpha_{n, i}\right) \sum_{l=1}^{M}\left\|\mathcal{P}_{C}^{l-1} u_{n}-\mathcal{P}_{C}^{l-1} p-\mathcal{P}_{C}^{l} u_{n}+\mathcal{P}_{C}^{l} p\right\|^{2} \\
& +\sum_{l=1}^{M} 2 \lambda_{l}\left\|\mathcal{P}_{C}^{l-1} u_{n}-\mathcal{P}_{C}^{l-1} p-\mathcal{P}_{C}^{l} u_{n}+\mathcal{P}_{C}^{l} p\right\|\left\|A_{l} \mathcal{P}_{C}^{l-1} u_{n}-A_{l} \mathcal{P}_{C}^{l-1} p\right\| .
\end{aligned}
$$

This implies that

$$
\begin{aligned}
\left(1-\alpha_{n, i}\right) & \sum_{l=1}^{M}\left\|\mathcal{P}_{C}^{l-1} u_{n}-\mathcal{P}_{C}^{l-1} p-\mathcal{P}_{C}^{l} u_{n}+\mathcal{P}_{C}^{l} p\right\|^{2} \\
\leq & \alpha_{n, i}\left\|x_{0}-p\right\|^{2}+\left\|x_{n}-p\right\|^{2}-\left\|y_{n, i}-p\right\|^{2} \\
& +\sum_{l=1}^{M} 2 \lambda_{l}\left\|\mathcal{P}_{C}^{l-1} u_{n}-\mathcal{P}_{C}^{l-1} p-\mathcal{P}_{C}^{l} u_{n}+\mathcal{P}_{C}^{l} p\right\|\left\|A_{l} \mathcal{P}_{C}^{l-1} u_{n}-A_{l} \mathcal{P}_{C}^{l-1} p\right\| \\
\leq & \alpha_{n, i}\left\|x_{0}-p\right\|^{2}+\left\|x_{n}-y_{n, i}\right\|\left(\left\|x_{n}-p\right\|+\left\|y_{n, i}-p\right\|\right) \\
& +\sum_{l=1}^{M} 2 \lambda_{l}\left\|\mathcal{P}_{C}^{l-1} u_{n}-\mathcal{P}_{C}^{l-1} p-\mathcal{P}_{C}^{l} u_{n}+\mathcal{P}_{C}^{l} p\right\|\left\|A_{l} \mathcal{P}_{C}^{l-1} u_{n}-A_{l} \mathcal{P}_{C}^{l-1} p\right\| .
\end{aligned}
$$

Then, by condition (iv), (34) and (42), we obtain that

$$
\lim _{n \rightarrow \infty}\left\|\mathcal{P}_{C}^{l-1} u_{n}-\mathcal{P}_{C}^{l-1} p-\mathcal{P}_{C}^{l} u_{n}+\mathcal{P}_{C}^{l} p\right\|=0
$$

Therefore, we have

$$
\left\|u_{n}-w_{n}\right\|=\left\|\mathcal{P}_{C}^{0} u_{n}-\mathcal{P}_{C}^{l} u_{n}\right\| \leq \sum_{l=1}^{M}\left\|\mathcal{P}_{C}^{l-1} u_{n}-\mathcal{P}_{C}^{l-1} p-\mathcal{P}_{C}^{l} u_{n}+\mathcal{P}_{C}^{l} p\right\|^{2} \rightarrow 0 \text { as } n \rightarrow \infty .
$$

On the other hand, by condition (iv) implies that

$$
\left\|y_{n, i}-\frac{1}{t_{n}} \int_{0}^{t_{n}} S(s) W_{n} w_{n} d s\right\|^{2}=\alpha_{n, i}\left\|x_{0}-\frac{1}{t_{n}} \int_{0}^{t_{n}} S(s) W_{n} w_{n} d s\right\| \rightarrow 0, \forall i \geq 1
$$


it follows that

$$
\left\|x_{n}-\frac{1}{t_{n}} \int_{0}^{t_{n}} S(s) W_{n} w_{n} d s\right\| \leq\left\|x_{n}-y_{n, i}\right\|+\left\|y_{n, i}+\frac{1}{t_{n}} \int_{0}^{t_{n}} S(s) W_{n} w_{n} d s\right\| \rightarrow 0 .
$$

Step 4. We show that $z \in \Theta:=F(\mathcal{S}) \cap\left(\cap_{i=1}^{\infty} F\left(T_{i}\right)\right) \cap\left(\cap_{k=1}^{N} \operatorname{SMEP}\left(F_{k}\right)\right) \cap \operatorname{GSVI}\left(C, A_{l}\right), \forall l \in\{1,2, \ldots, M\}$. Since $\left\{w_{n_{i}}\right\}$ is bounded, there exists a subsequence $\left\{w_{n_{i_{j}}}\right\}$ of $\left\{w_{n_{i}}\right\}$ which converges weakly to $z \in C$. Without loss of generality, we can assume that $w_{n_{i}} \rightarrow z$.

(1) First, we prove that $z \in F(\mathcal{S})$. From (38), (47), and (49), we get

$$
\lim _{n \rightarrow \infty}\left\|w_{n}-\frac{1}{t_{n}} \int_{0}^{t_{n}} S(s) W_{n} w_{n} d s\right\|=0 .
$$

Since $\left\{W_{n} w_{n}\right\}$ is a bounded and from Lemma 2.5 for any $h \geq 0$, we have

$$
\lim _{n \rightarrow \infty}\left\|\frac{1}{t_{n}} \int_{0}^{t_{n}} S(s) W_{n} w_{n} d s-S(h)\left(\frac{1}{t_{n}} \int_{0}^{t_{n}} S(s) W_{n} w_{n} d s\right)\right\|=0,
$$

and since

$$
\begin{aligned}
\left\|w_{n}-S(h) w_{n}\right\| & \leq\left\|w_{n}-\frac{1}{t_{n}} \int_{0}^{t_{n}} S(s) W_{n} w_{n} d s\right\|+\left\|\frac{1}{t_{n}} \int_{0}^{t_{n}} S(s) W_{n} w_{n} d s-S(h) \frac{1}{t_{n}} \int_{0}^{t_{n}} S(s) W_{n} w_{n} d s\right\| \\
& +\left\|S(h) \frac{1}{t_{n}} \int_{0}^{t_{n}} S(s) W_{n} w_{n} d s-S(h) w_{n}\right\| \\
& \leq 2\left\|w_{n}-\frac{1}{t_{n}} \int_{0}^{t_{n}} S(s) W_{n} w_{n} d s\right\|+\left\|\frac{1}{t_{n}} \int_{0}^{t_{n}} S(s) W_{n} w_{n} d s-S(h) \frac{1}{t_{n}} \int_{0}^{t_{n}} S(s) W_{n} w_{n} d s\right\|
\end{aligned}
$$

for all $0 \leq s<\infty$. It follows from (50) and (51), we get

$$
\lim _{n \rightarrow \infty}\left\|w_{n}-S(h) w_{n}\right\|=0 .
$$

Indeed, from Lemma 2.6 and (52), we get $z \in F(\mathcal{S})$, i.e., $z=S(s) z, \forall s \geq 0$.

(2) Next, we show that $z \in F(W)=\cap_{n=1}^{\infty} F\left(W_{n}\right)=\cap_{i=1}^{\infty} F\left(T_{i}\right)$, where $F\left(W_{n}\right)=\cap_{i=1}^{n} F\left(T_{i}\right), \forall n \geq 1$ and $F\left(W_{n+1}\right) \subset F\left(W_{n}\right)$. Assume that $z \notin F(W)$, then there exists a positive integer $m$ such that $z \notin F\left(T_{m}\right)$ and so $z \notin \cap_{i=1}^{m} F\left(T_{i}\right)$. Hence for any $n \geq m, z \notin \cap_{i=1}^{n} F\left(T_{i}\right)=F\left(W_{n}\right)$, i.e., $z \neq W_{n} z$. This together with $z=S(s) z, \forall s$ $\geq 0$ shows $z=S(s) z \neq S(s) W_{n} z, \quad \forall s \geq 0$, therefore we have $z \neq \frac{1}{t_{n}} \int_{0}^{t_{n}} S(s) W_{n} z d s, \forall n \geq m$. It follows from the Opial's condition and (50) that

$$
\begin{aligned}
\liminf _{i \rightarrow \infty}\left\|w_{n_{i}}-z\right\| & <\liminf _{i \rightarrow \infty}\left\|w_{n_{i}}-\frac{1}{t_{n_{i}}} \int_{0}^{t_{n_{i}}} S(s) W_{n_{i}} z d s\right\| \\
\leq & \liminf _{i \rightarrow \infty}\left(\left\|w_{n_{i}}-\frac{1}{t_{n_{i}}} \int_{0}^{t_{n_{i}}} S(s) W_{n_{i}} w_{n_{i}} d s\right\|\right. \\
& \left.\quad+\left\|\frac{1}{t_{n_{i}}} \int_{0}^{t_{n_{i}}} S(s) W_{n_{i}} w_{n_{i}} d s-\frac{1}{t_{n_{i}}} \int_{0}^{t_{n_{i}}} S(s) W_{n_{i}} z d s\right\|\right) \\
\leq & \liminf _{i \rightarrow \infty}\left\|w_{n_{i}}-z\right\|,
\end{aligned}
$$


which is a contradiction. Thus, we get $z \in \cap_{i=1}^{\infty} F\left(T_{i}\right)$.

(3) We prove that $z \in \cap_{k=1}^{N} \operatorname{SMEP}\left(F_{k}, \varphi\right)$. Since $\Im_{n}^{k}=\mathcal{K}_{r_{k}}^{F_{k}}, k=1,2, \ldots, N$ and $u_{n}^{k}=\Im_{n}^{k} x_{n}$, we have

$$
F_{k}\left(\Im_{n}^{k} x_{n}, x\right)+\varphi(x)-\varphi\left(\Im_{n}^{k} x_{n}\right)+\frac{1}{r_{k}}\left\langle\mathcal{K}^{\prime}\left(\Im_{n}^{k} x_{n}\right)-\mathcal{K}^{\prime}\left(\Im_{n}^{k-1} x_{n}\right), \eta\left(x, \Im_{n}^{k} x_{n}\right)\right\rangle \geq 0, \quad \forall x \in C .
$$

It follows that

$$
\frac{1}{r_{k}}\left\langle\mathcal{K}^{\prime}\left(\Im_{n_{i}}^{k} x_{n_{i}}\right)-\mathcal{K}^{\prime}\left(\Im_{n_{i}}^{k-1} x_{n_{i}}\right), \eta\left(x, \Im_{n_{i}}^{k} x_{n_{i}}\right)\right\rangle \geq-F_{k}\left(\Im_{n_{i}}^{k} x_{n_{i}} x\right)-\varphi(x)+\varphi\left(\Im_{n_{i}}^{k} x_{n_{i}}\right)
$$

for all $x \in C$. From (36) and by conditions (i)(3) and (ii), we get

$$
\lim _{n_{i} \rightarrow \infty} \frac{1}{r_{k}}\left\langle\mathcal{K}^{\prime}\left(\Im_{n_{i}}^{k} x_{n_{i}}\right)-\mathcal{K}^{\prime}\left(\Im_{n_{i}}^{k-1} x_{n_{i}}\right), \eta\left(x, \Im_{n_{i}}^{k} x_{n_{i}}\right)\right\rangle=0 .
$$

By the assumption and by the condition (H1), we know that the function $\phi$ and the mapping $x \mapsto\left(-F_{k}(x, y)\right)$ both are convex and lower semicontinuous, hence they are weakly lower semicontinuous. These together with $\frac{\mathcal{K}^{\prime}\left(\Im_{n_{i}}^{k} x_{n_{i}}\right)-\mathcal{K}^{\prime}\left(\Im_{n_{i}}^{k-1} x_{n_{i}}\right)}{r_{k}} \rightarrow 0$ and $\Im_{n_{i}}^{k} x_{n_{i}} \rightarrow z, \quad$ we have $0=\liminf _{n_{i} \rightarrow \infty}\left\langle\frac{\mathcal{K}^{\prime}\left(\Im_{n_{i}}^{k} x_{n_{i}}\right)-\mathcal{K}^{\prime}\left(\Im_{n_{i}}^{k-1} x_{n_{i}}\right)}{r_{k}}, \eta\left(x, \Im_{n_{i}}^{k} x_{n_{i}}\right)\right\rangle \geq \liminf _{n_{i} \rightarrow \infty}\left\{-F_{k}\left(\Im_{n_{i}}^{k} x_{n_{i}} x\right)-\varphi(x)+\varphi\left(\Im_{n_{i}}^{k} x_{n_{i}}\right)\right\}$.

Then, we obtain

$$
F_{k}(z, x)+\varphi(x)-\varphi(z) \geq 0, \quad \forall x \in C, \quad \forall k=, 1,2, \ldots, N .
$$

Therefore $z \in \cap_{k=1}^{N} \operatorname{SMEP}\left(F_{k}, \varphi\right)$.

(4) Last, we show that $z \in G \operatorname{GVI}\left(C, A_{l}\right), \forall l \in\{1,2, \ldots, M\}$. By the nonexpansivity of $\mathcal{P}$ in Lemma 2.7, we have

$$
\begin{aligned}
\left\|w_{n}-\mathcal{P}\left(w_{n}\right)\right\| & =\left\|P_{C}\left(I-\lambda_{M} A_{M}\right) P_{C}\left(I-\lambda_{M-1} A_{M-1}\right) \ldots P_{C}\left(I-\lambda_{2} A_{2}\right) P_{C}\left(I-\lambda_{1} A_{1}\right) u_{n}-\mathcal{P}\left(w_{n}\right)\right\| \\
& =\left\|\mathcal{P}\left(u_{n}\right)-\mathcal{P}\left(w_{n}\right)\right\| \\
& \leq\left\|u_{n}-w_{n}\right\| .
\end{aligned}
$$

We note that

$$
\left\|x_{n}-w_{n}\right\| \leq\left\|x_{n}-u_{n}\right\|+\left\|u_{n}-w_{n}\right\| .
$$

Therefore, we conclude that $\lim _{n \rightarrow \infty}\left\|w_{n}-\mathcal{P}\left(w_{n}\right)\right\|=0$ and $\lim _{n \rightarrow \infty}\left\|x_{n}-w_{n}\right\|=0$. Since $\mathcal{P}$ is nonexpansive, we get

$$
\begin{aligned}
\left\|x_{n}-\mathcal{P}\left(x_{n}\right)\right\| & \leq\left\|x_{n}-w_{n}\right\|+\left\|w_{n}-\mathcal{P}\left(w_{n}\right)\right\|+\left\|\mathcal{P}\left(w_{n}\right)-\mathcal{P}\left(x_{n}\right)\right\| \\
& \leq 2\left\|x_{n}-w_{n}\right\|+\left\|w_{n}-\mathcal{P}\left(w_{n}\right)\right\| .
\end{aligned}
$$

According to Lemma 2.9, we obtain that $z \in \operatorname{GSVI}\left(C, A_{l}\right)$ for all $l \in\{1,2, \ldots, M\}$. Hence by (1)-(4), we have $z \in \Theta$.

Step 5. Noting that $x_{n}=P_{C_{n}} x_{0}$. By (15), we have

$$
\left\langle x_{0}-x_{n}, y-x_{n}\right\rangle \leq 0, \quad \forall y \in C_{n} .
$$


Since $\Theta \subset C_{n}$ and by the continuity of inner product, we obtain from the above inequality that

$$
\left\langle x_{0}-z, y-z\right\rangle \leq 0, \quad \forall y \in C .
$$

By (15) again, we conclude that $z=P_{\Theta} x_{0}$. This completes the proof.

Corollary 3.2. Let $C$ be a nonempty closed convex subset of a real Hilbert Space $H$. Let $F: C \times C \rightarrow \mathbb{R}$ be a bifunctions satisfying conditions (H1)-(H3). Let $A$ be a $\beta$ inverse-strongly monotone mappings of $C$ into $H$. Let $\mathcal{S}=\{S(s): 0 \leq s<\infty\}$ be a nonexpansive semigroup on $C$ and let $\left\{t_{n}\right\}$ be a positive real divergent sequence. Suppose that $\Theta:=F(\mathcal{S}) \cap \operatorname{MEP}(F, \varphi) \cap \operatorname{VI}(C, A) \neq \varnothing$. Let $\left\{x_{n}\right\}$ be a sequence generated by $x_{0} \in C, \quad C_{1, i}=C, \quad C_{1}=\cap_{i=1}^{\infty} C_{1, i}, x_{1}=P_{C_{1}} x_{0}$ and

$$
\left\{\begin{array}{l}
u_{n}=K_{r}^{F} x_{n} \\
w_{n}=P_{C}(I-\lambda A) u_{n} \\
y_{n, i}=\alpha_{n, i} x_{0}+\left(1-\alpha_{n, i}\right) \frac{1}{t_{n}} \int_{0}^{t_{n}} S(s) w_{n} d s \\
C_{n+1, i}=\left\{z \in C_{n, i}:\left\|y_{n, i}-z\right\|^{2} \leq\left\|x_{n}-z\right\|^{2}+\alpha_{n, i}\left(\left\|x_{0}\right\|^{2}+2\left\langle x_{n}-x_{0}, z\right\rangle\right)\right\} \\
C_{n+1}=\bigcap_{i=1}^{\infty} C_{n+1, i} \\
x_{n+1}=P_{C_{n+1}} x_{0}
\end{array}\right.
$$

for every $n \geq 0$, where $K_{r}^{F}: C \rightarrow C$ is the mapping defined by (24), $r>0$ is a constant and $\left\{\alpha_{n, i}\right\}_{n=1}^{\infty} \subset(0,1)$ satisfy the conditions (i)-(vi). Then, $\left\{x_{n}\right\}$ converges strongly to $P_{\Theta} x_{0}$.

Proof. Putting $W_{n}=I$ (Identity mapping), $M=1$ and $N=1$ in Theorem 3.1, we can conclude the desired conclusion easily. This completes the proof.

\section{Deduced theorems}

In this section, we deduce Theorem 3.1 to obtain the following four corollaries.

Corollary 4.1. Let $C$ be a nonempty closed convex subset of a real Hilbert Space $H$. Let $\mathcal{S}=\{S(s): 0 \leq s<\infty\}$ be a nonexpansive semigroup on $C$ and let $\left\{t_{n}\right\}$ be a positive real divergent sequence. Suppose that $F(\mathcal{S}) \neq \emptyset$. Let $\left\{x_{n}\right\}$ be a sequence generated by $x_{0} \in C, \quad C_{1, i}=C, \quad C_{1}=\cap_{i=1}^{\infty} C_{1, i}, x_{1}=P_{C_{1}} x_{0}$ and

$$
\left\{\begin{array}{l}
y_{n, i}=\alpha_{n, i} x_{0}+\left(1-\alpha_{n, i}\right) \frac{1}{t_{n}} \int_{0}^{t_{n}} S(s) x_{n} d s \\
C_{n+1, i}=\left\{z \in C_{n, i}:\left\|y_{n, i}-z\right\|^{2} \leq\left\|x_{n}-z\right\|^{2}+\alpha_{n, i}\left(\left\|x_{0}\right\|^{2}+2\left\langle x_{n}-x_{0}, z\right\rangle\right)\right\} \\
C_{n+1}=\cap_{i=1}^{\infty} C_{n+1, i} \\
x_{n+1}=P_{C_{n+1}} x_{0}
\end{array}\right.
$$

for every $n \geq 0$, where $\left\{\alpha_{n, i}\right\}_{n=1}^{\infty} \subset(0,1)$ satisfy the condition (iv). Then, $\left\{x_{n}\right\}$ converges strongly to $P_{F(\mathcal{S})} x_{0}$.

Proof. Putting $W_{n}=K_{r_{k}}^{F_{k}}=I, \forall k=1,2, \ldots, N$ (Identity mappings) and $A_{l}=0, \forall l \in\{1$, $2, \ldots, M\}$ in Theorem 3.1, we can conclude the desired conclusion easily. This completes the proof.

Corollary 4.2. Let $C$ be a nonempty closed convex subset of a real Hilbert Space $H$. Let $\left\{V_{i}: C \rightarrow C\right\}_{i=1}^{\infty}$ be a countable family of uniformly $k$-strict pseudo-contractions, $\left\{T_{i}: C \rightarrow C\right\}_{i=1}^{\infty}$ be a countable family of nonexpansive mappings defined by $T_{i} x=t x$ $+(1-t) V_{i} x, \forall x \in C, \forall i \geq 1, t \in[k, 1)$. Suppose that $\Theta:=\cap_{i=1}^{\infty} F\left(T_{i}\right) \neq \emptyset$. Let $\left\{x_{n}\right\}$ be a sequence generated by $x_{0} \in C, C_{1, i}=C, C_{1}=\cap_{i=1}^{\infty} C_{1, i}, x_{1}=P_{C_{1}} x_{0}$ and 


$$
\left\{\begin{array}{l}
y_{n, i}=\alpha_{n, i} x_{0}+\left(1-\alpha_{n, i}\right) W_{n} x_{n} \\
C_{n+1, i}=\left\{z \in C_{n, i}:\left\|y_{n, i}-z\right\|^{2} \leq\left\|x_{n}-z\right\|^{2}+\alpha_{n, i}\left(\left\|x_{0}\right\|^{2}+2\left\langle x_{n}-x_{0}, z\right\rangle\right)\right\} \\
C_{n+1}=\cap_{i=1}^{\infty} C_{n+1, i} \\
x_{n+1}=P_{C_{n+1}} x_{0}
\end{array}\right.
$$

for every $n \geq 0$, where $\left\{\alpha_{n, i}\right\}_{n=1}^{\infty} \subset(0,1)$ satisfy the condition (iv). Then, $\left\{x_{n}\right\}$ converges strongly to $P_{\Theta} x_{0}$.

Proof. Taking $K_{r_{k}}^{F_{k}}=I, \forall k=1,2, \ldots, N$ (Identity mapping), $s=0$ and $A_{l}=0, \forall l \in\{1$, $2, \ldots, M\}$ in Theorem 3.1, we can conclude the desired conclusion easily. This completes the proof.

Corollary 4.3. Let $C$ be a nonempty closed convex subset of a real Hilbert Space $H$. Let $\left\{F_{k}: C \times C \rightarrow \mathbb{R}, k=1,2, \ldots, N\right\}$ be a finite family of bifunctions satisfying conditions (H1)-(H3). Suppose that $\Theta:=\cap_{k=1}^{N} \operatorname{SMEP}\left(F_{k}\right) \neq \emptyset$. Let $\left\{x_{n}\right\}$ be a sequence generated by $x_{0} \in C, C_{1, i}=C, \quad C_{1}=\cap_{i=1}^{\infty} C_{1, i}, \quad x_{1}=P_{C_{1}} x_{0}$ and

$$
\left\{\begin{array}{l}
u_{n}=K_{r_{N, n}}^{F_{N}} K_{r_{N-1, n}}^{F_{N-1}} \ldots K_{r_{2, n}}^{F_{2}} K_{r_{1, n}}^{F_{1}} x_{n} \\
y_{n, i}=\alpha_{n, i} x_{0}+\left(1-\alpha_{n, i}\right) u_{n} \\
C_{n+1, i}=\left\{z \in C_{n, i}:\left\|y_{n, i}-z\right\|^{2} \leq\left\|x_{n}-z\right\|^{2}+\alpha_{n, i}\left(\left\|x_{0}\right\|^{2}+2\left\langle x_{n}-x_{0}, z\right\rangle\right)\right\} \\
C_{n+1}=\cap_{i=1}^{\infty} C_{n+1, i} \\
x_{n+1}=P_{C_{n+1}} x_{0}
\end{array}\right.
$$

for every $n \geq 0$, where $K_{r}^{F}: C \rightarrow C$ is the mapping defined by (24), $r>0$ is a constant and $\left\{\alpha_{n, i}\right\}_{n=1}^{\infty} \subset(0,1)$ satisfy the conditions (i)-(iv) and (vi). Then, $\left\{x_{n}\right\}$ converges strongly to $P_{\Theta} x_{0}$.

Proof. Putting $W_{n}=I$ (identity mapping), $A_{l}=0, \forall l \in\{1,2, \ldots, M\}$ and $s=0$ in Theorem 3.1, we can conclude the desired conclusion easily. This completes the proof.

Corollary 4.4. Let $C$ be a nonempty closed convex subset of a real Hilbert Space $H$. Let $A_{l}$ be $\beta_{l}$-inverse-strongly monotone mappings of $C$ into $H$, where $l \in\{1,2, \ldots, M\}$. For $l \in\{1,2, \ldots, M\}$, suppose that $\Theta:=\operatorname{GSVI}\left(C, A_{l}\right) \neq \emptyset$. Let $\left\{x_{n}\right\}$ be a sequence generated by $x_{0} \in C, C_{1, i}=C, C_{1}=\cap_{i=1}^{\infty} C_{1, i}, x_{1}=P_{C_{1}} x_{0}$ and

$$
\left\{\begin{array}{l}
w_{n}=P_{C}\left(I-\lambda_{M} A_{M}\right) P_{C}\left(I-\lambda_{M-1} A_{M-1}\right) \ldots P_{C}\left(I-\lambda_{2} A_{2}\right) P_{C}\left(I-\lambda_{1} A_{1}\right) x_{n} \\
y_{n, i}=\alpha_{n, i} x_{0}+\left(1-\alpha_{n, i}\right) w_{n} \\
C_{n+1, i}=\left\{z \in C_{n, i}:\left\|y_{n, i}-z\right\|^{2} \leq\left\|x_{n}-z\right\|^{2}+\alpha_{n, i}\left(\left\|x_{0}\right\|^{2}+2\left\langle x_{n}-x_{0}, z\right\rangle\right)\right\} \\
C_{n+1}=\cap_{i=1}^{\infty} C_{n+1, i} \\
x_{n+1}=P_{C_{n+1}} x_{0}
\end{array}\right.
$$

for every $n \geq 0$, where $\left\{\alpha_{n, i}\right\}_{n=1}^{\infty} \subset(0,1)$ satisfy the conditions (iv) and (v). Then, $\left\{x_{n}\right\}$ converges strongly to $P_{F(\mathcal{S})} x_{0}$.

Proof. Taking $W_{n}=K_{r_{k}}^{F_{k}}=I, \forall k=1,2, \ldots, N$ (identity mapping) and $s=0$ in Theorem 3.1, we can conclude the desired conclusion easily. This completes the proof.

\section{Acknowledgements}

P. Kumam would like to thank the Higher Education Research Promotion and National Research University Project of Thailand, Office of the Higher Education Commission (NRU-CSEC No. 55000613) for financial support. Furthermore, P. Katchang gratefully acknowledges support provided by the King Mongkut's University of Technology Thonburi (KMUTT) during the second author's stay at the King Mongkut's University of Technology Thonburi (KMUTT) as a post doctoral fellow (KMUTT-Post-doctoral Fellowship). 


\section{Author details}

'Department of Mathematics, Faculty of Science, King Mongkut's University of Technology Thonburi (KMUTT), Bangmod, Bangkok 10140, Thailand ${ }^{2}$ Department of Mathematics and Statistics, Faculty of Science and Agricultural Technology, Rajamangala University of Technology Lanna Tak, Tak 63000, Thailand

\section{Authors' contributions}

Both authors read and approved the final manuscript.

\section{Competing interests}

The authors declare that they have no competing interests.

Received: 31 October 2011 Accepted: 18 May 2012 Published: 18 May 2012

\section{References}

1. Verma, RU: On a new system of nonlinear variational inequalities and associated iterative algorithms. Math Sci Res HotLine. 3(8), 65-68 (1999)

2. Verma, RU: Iterative algorithms and a new system of nonlinear quasivariational inequalities. Adv Nonlinear var Inequal. 4(1), 117-124 (2001)

3. Stampacchia, G: Formes bilineaires coercitives sur les ensembles convexes. C R Acad Sci Paris. 258, 4413-4416 (1964)

4. Browder, FE, Petryshym, WV: Construction of fixed points of nonlinear mappings in Hilbert spaces. J Math Anal Appl. 20, 197-228 (1963)

5. Argyros, IK, Cho, YJ, Qin, X: On the implicit iterative process for strictly pseudo-contractive mappings in Banach spaces. J Comput Appl Math. 233, 208-216 (2009). doi:10.1016/j.cam.2009.07.011

6. Goebel, K, Kirk, WA: Topics on Metric Fixed-Point Theory. Cambridge University Press, Cambridge (1990)

7. Flores-Bazán, F: Existence theorems for generalized noncoercive equilibrium problems: the quasiconvex case. SIAM J Optim. 11(3), 675-690 (2000)

8. Combettes, PL, Hirstaoga, SA: Equilibrium programming in Hilbert spaces. J Nonlinear Convex Anal. 6, 117-136 (2005)

9. Burachik, RS, Lopes, JO: An inexact interior point proximal method for the variational inequality problem. Comput Appl Math. 28, 15-36 (2009)

10. Blum, E, Oettli, W: From optimization and variational inequalities to equilibrium problems. Math Student. $63,123-145$ (1994)

11. Chadli, O, Wong, NC, Yao, JC: Equilibrium problems with applications to eigenvalue problems. J Optim Theory Appl. 117(2), 245-266 (2003). doi:10.1023/A:1023627606067

12. Chadli, O, Schaible, S, Yao, JC: Regularized equilibrium problems with application to noncoercive hemivariational inequalities. J Optim Theory Appl. 121(3), 571-596 (2004)

13. Flam, SD, Antipin, AS: Equilibrium programming using proximal-link algorithms. Math Program. 78, 29-41 (1997)

14. Moudafi, A, Thera, M: Proximal and dynamical approaches to equilibrium problems, Lecture note in Economics and Mathematical Systems. pp. 187-201. Springer-Verlag, New York477, (1999)

15. Wang, Z, Su, Y: Strong convergence theorems of common elements for equilibrium problems and fixed point problems in Banach paces. J Appl Math Inf. 28(3-4), 783-796 (2010)

16. Wangkeeree, R, Wangkeeree, R: Strong convergence of the iterative scheme based on the extragradient method for mixed equilibrium problems and fixed point problems of an infinite family of nonexpansive mappings. Nonlinear Anal Hybrid Syst. 3(4), 719-733 (2009). doi:10.1016/j.nahs.2009.06.009

17. Yao, Y, Aslam Noor, M, Zainab, S, Liou, YC: Mixed equilibrium problems and optimization problems. J Math Anal Appl. 354(1), 319-329 (2009). doi:10.1016/j.jmaa.2008.12.055

18. Yao, Y, Cho, YJ, Chen, R: An iterative algorithm for solving fixed point problems, variational inequality problems and mixed equilibrium problems. Nonlinear Anal. 71, 3363-3373 (2009). doi:10.1016/j.na.2009.01.236

19. Zeng, LC, Wu, SY, Yao, JC: Generalized KKM theorem with applications to generalized minimax inequalities and generalized equilibrium problems. Taiwanese J Math. 10(6), 1497-1514 (2006)

20. Peng, JW, Yao, JC: Strong convergence theorems of iterative scheme based on the extragradient method for mixed equilibrium problems and fixed point problems. Math Comput Model. 49, 1816-1828 (2009). doi:10.1016/j. $\mathrm{mcm} .2008 .11 .014$

21. Shehu, Y: Iterative methods for family of strictly pseudocontractive mappings and system of generalized mixed equilibrium problems and variational inequality problems. Fixed Point Theory and Applications 2011 (2011). Article ID 852789,22

22. Shimizu, T, Takahashi, W: Strong convergence to common fixed points of families of nonexpansive mappings. J Math Anal Appl. 211, 71-83 (1997). doi:10.1006/jmaa.1997.5398

23. Yao, Y, Cho, YJ, Liou, Y: Iterative algorithms for variational inclusions, mixed equilibrium problems and fixed point problems approach to optimization problems. Central Europ J Math. 9, 640-656 (2011). doi:10.2478/s11533-011-0021-3

24. Yao, Y, Cho, YJ, Liou, Y: Algorithms of common solutions for variational inclusions, mixed equilibrium problems and fixed point problems. Europ J Operat Res. 212, 242-250 (2011). doi:10.1016/j.ejor.2011.01.042

25. Chang, SS, Cho, YJ, Joseph Lee, HW, Chan, CK: Strong convergence theorems for Lipschitzian demi-contraction semigroups in Banach spaces. Fixed Point Theory Appl 2011 (2011). Article ID 583423, 10

26. Yao, Y, Cho, YJ, Liou, YC: Hierarchical convergence of an implicit double-net algorithm for nonexpansive semigroups and variational inequality problems. Fixed Point Theory Appl 2011 (2011). 101

27. Chen, JW, Cho, YJ, Wan, Z: Shrinking projection algorithms for equilibrium problems with a bifunction defined on the dual space of a Banach space. Fixed Point Theory Appl. 91, 2011 (2011)

28. Cho, YJ, Kang, Jl, Qin, X: Convergence theorems based on hybrid methods for generalized equilibrium problems and fixed point problems. Nonlinear Anal. 71, 4203-4214 (2009). doi:10.1016/.na.2009.02.106

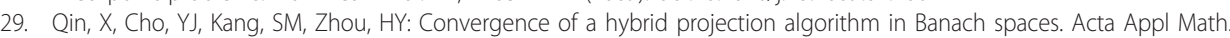
108, 299-313 (2009). doi:10.1007/s10440-008-9313-4 
30. Zhou, H: Convergence theorems of fixed Points for k-strict pseudo-contractions in Hilbert spaces. Nonlinear Anal. 69, 456-462 (2008). doi:10.1016/j.na.2007.05.032

31. Shimoji, K, Takahashi, W: Strong convergence to common fixed points of infinite non-expansive mappings and applications. Taiwanese J Math. 5, 387-404 (2001)

32. Chang, SS: Variational Inequalities and Related Problems. Chongqing Publishing House, Chongqing (2007) (in Chinese)

33. Opial, Z: Weak convergence of the sequence of successive approximations for nonexpan-sive mappings. Bull Am Math Soc. 73, 595-597 (1967)

34. Tan, KK, Xu, HK: The nonlinear ergodic theorem for asymptotically nonexpansive mappings in Banach spaces. Proc Am Math Soc. 114, 399-404 (1992). doi:10.1090/S0002-9939-1992-1068133-2

35. Ceng, LC, Yao, JC: A hybrid iterative scheme for mixed equilibrium problems and fixed point problems. J Comput Appl Math. 214, 186-201 (2008). doi:10.1016/j.cam.2007.02.022

doi:10.1186/1687-1812-2012-84

Cite this article as: Kumam and Katchang: The hybrid algorithm for the system of mixed equilibrium problems,

the general system of finite variational inequalities and common fixed points for nonexpansive semigroups and strictly pseudo-contractive mappings. Fixed Point Theory and Applications 2012 2012:84.

\section{Submit your manuscript to a SpringerOpen ${ }^{\circ}$} journal and benefit from:

$\rightarrow$ Convenient online submission

Rigorous peer review

- Immediate publication on acceptance

- Open access: articles freely available online

- High visibility within the field

- Retaining the copyright to your article

Submit your next manuscript at $\gg$ springeropen.com 